\title{
High Mobility Group Box 1 Promotes Small Intestinal Damage Induced by Nonsteroidal Anti-Inflammatory Drugs through Toll-Like Receptor 4
}

Yuji Nadatani, Toshio Watanabe, Tetsuya Tanigawa, Hirohisa Machida, Hirotoshi Okazaki, Hirokazu Yamagami, Kenji Watanabe, Kazunari Tominaga, Yasuhiro Fujiwara, and Tetsuo Arakawa

From the Department of Gastroenterology, Osaka City University Graduate School of Medicine, Osaka, Japan

Release of high mobility group box 1 (HMGB1) from damaged cells, which is involved in many types of tissue injuries, activates inflammatory pathways by stimulating multiple receptors, including Toll-like receptor 2 (TLR2), TLR4, and receptor for advanced glycation end-products (RAGE). Our objective was to determine the role of HMGB1 in nonsteroidal anti-inflammatory drug (NSAID)-induced damage of the small intestine. Oral indomethacin $(10 \mathrm{mg} / \mathrm{kg})$ induced damage to the small intestine and was associated with increases in intestinal HMGB1 expression and serum HMGB1 levels. In wild-type mice, recombinant human HMGB1 aggravated indomethacin-induced small intestinal damage; enhanced the mRNA expression levels of tumor necrosis factor $\alpha$ (TNF$\alpha$ ), monocyte chemotactic protein 1, and KC; activated nuclear factor kappa B; and stimulated phosphorylation of the mitogen-activated protein kinases p38, extracellular signal-regulated kinase (ERK), and c-Jun N-terminal kinase (JNK). In contrast, blocking HMGB1 action with neutralizing antibodies prevented damage and inhibited both inflammatory cytokine overexpression and activation of these intracellular signaling pathways. TLR2-knockout (KO) and RAGE-KO mice exhibited high sensitivities to indomethacin-induced damage, similar to wild-type mice, whereas TLR4-KO mice exhibited less severe intestinal damage and lower levels of TNF- $\alpha$ mRNA expression. Exogenous HMGB1 aggravated the damage in TLR2- and RAGE-KO mice but did not affect the damage in TLR4-KO mice. Thus, our results suggest that HMGB1 promotes NSAID-induced small intestinal damage through TLR4-dependent signaling pathways. (Am J Pathol 2012, 181: 98-110; http://dx.doi.org/10.1016/j.ajpath.2012.03.039)
Patients with chronic arthritic conditions, such as rheumatoid arthritis and osteoarthritis, take nonsteroidal antiinflammatory drugs (NSAIDs) for long periods of time. Although these drugs are effective in reducing joint pain, stiffness, and swelling, their use is associated with a broad spectrum of adverse reactions in the liver, kidney, cardiovascular system, and gastrointestinal (GI) tract. Although it has been believed that the gastroduodenal mucosa is most susceptible to NSAID toxicology in the Gl tract, recent advances in small intestinal endoscopy, such as video capsule endoscopy and double-balloon endoscopy, have revealed that NSAIDs have strong ulcerogenic effects in the small intestine. Graham et al ${ }^{1}$ reported that small bowel injury was observed in 15 of 21 chronic NSAID users $(71 \%)$ by video capsule endoscopy. In addition, Sugimori et $\mathrm{al}^{2}$ detected mucosal breaks, such as ulcers and erosions, in the small intestine in 13 of $16(81.3 \%)$ rheumatoid arthritis patients who took a NSAID for more than 1 year. Because acid suppressants, such as proton pump inhibitors and $\mathrm{H}_{2}$ receptor antagonists, are effective for treating NSAID-induced injuries in the upper Gl tract but do not prevent those injuries in the small intestine, ${ }^{3}$ the precise mechanisms by which NSAIDs injure the small intestine must be clarified in order to develop new therapies for the prevention and treatment of NSAID-induced enteropathy.

We have previously demonstrated that NSAIDs injure the small intestine through activation of the Toll-like receptor 4 (TLR4)-dependent signaling pathway. ${ }^{4}$ TLR4 is a member of the TLR family, which plays a crucial role in innate immune responses to microbial pathogens. ${ }^{5}$ TLR4 recognizes primarily lipopolysaccharide (LPS), which is the major cellwall component of Gram-negative bacteria. The triggering of the TLR4 signaling pathway by LPS leads to activation of nuclear factor $\kappa \mathrm{B}(\mathrm{NF}-\kappa \mathrm{B})$ through the accessory protein

Supported by a grant-in-aid from the Ministry of Education, Science, and Culture of Japan.

Accepted for publication March 20, 2012.

Address reprint requests to Yuji Nadatani, M.D., Department of Gastroenterology, Osaka City University Graduate School of Medicine, 1-4-3 Asahimachi, Abeno-ku, Osaka 545-8585, Japan. E-mail: dada@med. osaka-cu.ac.jp. 
MyD88 and subsequently to regulation of immune and inflammatory genes, including inflammatory cytokines such as tumor necrosis factor $\alpha$ (TNF- $\alpha$ ).

Several molecules, including high mobility group box 1 (HMGB1), act as endogenous TLR4 ligands. ${ }^{6}$ HMGB1, which is a member of the high mobility group protein superfamily, exists in all eukaryotic cells. It is a highly conserved protein, with $>95 \%$ amino acid identity between rodents and humans. It was initially discovered as a nuclear protein that interacts with DNA as a chromatin-associated nonhistone protein $^{7}$ and that stabilizes nucleosomes and regulates transcription of many genes in the nucleus. ${ }^{8}$ Once HMGB1 is released into the extracellular environment, it acts as an inflammatory cytokine (an alarmin). ${ }^{9}$ HMGB1 leaks out of cells during necrotic cell death, ${ }^{10}$ and it is actively secreted by monocytes and macrophages. ${ }^{10,11}$ HMGB1 exerts these proinflammatory effects through TLR2, which is a receptor for components of the Gram-positive bacterial cell wall, and through the receptor for advanced glycation end-products (RAGE), which is a multiligand receptor belonging to the immunoglobulin superfamily, as well as through TLR4. ${ }^{12}$ Similarly to TLR4, triggering of the TLR2 signaling pathway results in NF- $\kappa$ B activation. Binding of RAGE to its ligands activates mitogen-activated protein kinases (MAPKs), including extracellular signal-regulated kinase (ERK) and $\mathrm{p} 38$, which results in NF- $\kappa \mathrm{B}$ activation. ${ }^{13}$

HMGB1 causes inflammatory responses and tissue injuries in various organ systems, including colitis, ${ }^{14,15}$ pancreatitis, ${ }^{16}$ and ischemia-reperfusion (I-R) injuries of liver, ${ }^{17}$ heart, ${ }^{18}$ and kidney. ${ }^{19}$ In this study, we investigated the roles of HMGB1 and its receptors TLR2, TLR4, and RAGE in the pathogenesis of NSAID-induced small intestinal inflammation and damage in mice.

\section{Materials and Methods}

\section{Animals and Induction of Small Intestinal Damage}

TLR2- and TLR4-knockout mice (KO), which were originally generated by Dr. Shizuo Akira (Osaka University, Osaka, Japan) ${ }^{5}$ and backcrossed eight times on a C57BL/6 background, were obtained from Oriental Bioservice (Kyoto, Japan). RAGE-KO mice, which had been backcrossed eight times on a C57BL/6 background, were originally generated by and were a gift from Dr. Yasuhiko Yamamoto (Kanazawa Medical University, Kanazawa, Japan). ${ }^{20}$ Wildtype C57BL/6 mice were purchased from Charles River Japan (Atsugi, Japan) as the control strain for TLR2-KO, TLR4-KO, and RAGE-KO mice. In the animal experiments, specific pathogen-free 12-week-old male animals were used. All animals were housed in polycarbonate cages with paper-chip bedding. The cages were located in an air-conditioned biohazard room under a 12-hour light-dark cycle.

To induce small intestinal injury, we administered 10 $\mathrm{mg} / \mathrm{kg}$ of indomethacin, $40 \mathrm{mg} / \mathrm{kg}$ of naproxen, or 50 $\mathrm{mg} / \mathrm{kg} \mathrm{NS}$-398 (a selective cyclooxygenase-2 inhibitor) in a $0.5 \%$ carboxymethylcellulose solution by gavage to nonfasting animals. Animals were sacrificed 3, 12, or 24 hours later. To evaluate tissue damage, 1\% Evans Blue was injected intravenously 30 minutes before sacrifice, and the small intestine was opened along the antimesenteric attachment. The areas $\left(\mathrm{mm}^{2}\right)$ of the macroscopically visible lesions were measured and summed per small intestine; this sum was used as the lesion index. All animals had free access to food and water. All experimental procedures were approved by the Animal Care Committee of the Osaka City University Graduate School of Medicine.

\section{Experimental Groups}

To clarify the involvement of HMGB1 in indomethacininduced small intestinal injury, mice received intraperitoneal injections of 100 to $1000 \mu \mathrm{g} / \mathrm{kg}$ human recombinant HMGB1 (rHMGB1; Sigma-Aldrich, St. Louis, MO) or vehicle (PBS) at 0 and 3 hours after indomethacin treatment. (Each mouse was given two injections.) Additionally, mice were intraperitoneally administered neutralizing chicken anti-HMGB1 polyclonal antibody $(50 \mathrm{mg} / \mathrm{kg}$; Shino-Test, Tokyo, Japan), normal chicken IgY (50 mg/ kg; Sigma-Aldrich), or ethyl pyruvate (40 mg/kg; SigmaAldrich), which is an inhibitor of HMGB1 release, ${ }^{21}$ at 0 and 3 hours after indomethacin treatment. To determine the HMGB1 receptors responsible for the damage, TLR2$\mathrm{KO}, \mathrm{TLR} 4-\mathrm{KO}$, and RAGE-KO mice were administered 10 $\mathrm{mg} / \mathrm{kg}$ of indomethacin by gavage with or without intraperitoneal injections of $1000 \mu \mathrm{g} / \mathrm{kg}$ of rHMGB1. Experiments were performed using four to eight samples.

\section{Determination of mRNA Expression Levels of Inflammatory Mediators in Small Intestinal Tissue by Real-Time Quantitative RT-PCR}

Total RNA was isolated from small intestinal tissue using an ISOGEN kit (Nippon Gene, Tokyo, Japan) according to the manufacturer's protocol. Complementary DNA was acquired using a high-capacity RNA-to-cDNA kit (Life Technologies, Carlsbad, CA) according to the manufacturer's protocol. Real-time quantitative RT-PCR analyses were performed using an Applied Biosystems ABI 7500 Fast RTPCR system and software (Life Technologies, Foster City, $\mathrm{CA})$. The reaction mixture was prepared according to the manufacturer's protocol using the ABI TaqMan Fast universal PCR master mixture (Life Technologies). Thermal cycling conditions were 45 cycles of amplification at $95^{\circ} \mathrm{C}$ for 15 seconds and $60^{\circ} \mathrm{C}$ for 1 minute. Total RNA was subjected to real-time quantitative RT-PCR for the measurement of target genes using ABI TaqMan glyceraldehyde-3phosphate dehydrogenase (GADPH) control reagents, which were used as an internal standard. mRNA expression levels for HMGB1, TLR2, TLR4, RAGE, and a number of inflammatory mediators [TNF- $\alpha$, monocyte chemotactic protein-1 (MCP-1), and the mouse IL-8 homolog (KC)] in injured and normal small intestinal tissue were quantified using real-time RT-PCR and were standardized to GAPDH mRNA levels. mRNA expression levels are reported relative to the mean value in normal intestinal tissue. The primers and probes used for RT-PCR are given in Table 1. RAGE primers and probes were purchased from Applied Biosystems. 
$100 \quad$ Nadatani et al

AJP July 2012, Vol. 181, No. 1

Table 1. Primers and Probes

\begin{tabular}{|c|c|c|}
\hline Murine gene (protein) & Primers and probes & Sequence \\
\hline \multirow[t]{3}{*}{$\operatorname{Tnf}(\mathrm{TNF}-\alpha)$} & Forward & 5'-TCATGCACCACCATCAAGGA-3' \\
\hline & Reverse & $5^{\prime}-$ GAGGCAACCTGACCACTCTCC-3' \\
\hline & Probe & 5'-FAM-AATGGGCTTTCCGAATTCACTGGAGC-TAMRA-3' \\
\hline \multirow[t]{3}{*}{ Mcp1 (MCP-1) } & Forward & $5^{\prime}-$ CCACTCACCTGCTGCTACTCAT-3' \\
\hline & Reverse & 5'-GGTGATCCTCTTGTAGCTCTCCA-3' \\
\hline & Probe & 5'-FAM-CACCAGCAAGATGATCCCAATGAGTAGGTAMRA-TAMRA-3' \\
\hline \multirow[t]{3}{*}{$\mathrm{CxCl} / \mathrm{KC})$} & Forward & $5^{\prime}$-TCATCGATTTCTCCCCTGTGA-3' \\
\hline & Reverse & 5'-CTCGCGACCATTCTTGAGTGT-3' \\
\hline & Probe & $5^{\prime}-\mathrm{FAM}-\mathrm{CCCACTGCACCCAAACCGAAGTCATA-TAMRA}-3^{\prime}$ \\
\hline \multirow[t]{3}{*}{ TIr2 (TLR2) } & Forward & $5^{\prime}-$ CTCTGGAGCATCCGAATTGC $-3^{\prime}$ \\
\hline & Reverse & $5^{\prime}$-GCTGAAGAGGACTGTTATGGC-3' \\
\hline & Probe & 5'-CCTCAGACAAAGCGTCAAATCTCAGAGGA-TAMRA-3' \\
\hline \multirow[t]{3}{*}{ TIr4 (TLR4) } & Forward & $5^{\prime}$-GGCTGGATTTATCCAGGTGTGA-3' \\
\hline & Reverse & 5'-CTGTCAGTATCAAGTTTGAGAGGTG-3' \\
\hline & Probe & 5'-AGCCATGCCATGCCTTGTCTTCAATTGT-TAMRA-3' \\
\hline \multirow[t]{3}{*}{ Hmgb1 (HMBG1) } & Forward & $5^{\prime}$-CAGCCATTGCAGTACATTGAGC-3' \\
\hline & Reverse & 5'-TCTCCTTTGCCCATGTTTAGTTG-3' \\
\hline & Probe & $5^{\prime}$-GACAGAGTCGCCCAGTGCCCGTCC-TAMRA-3' \\
\hline
\end{tabular}

\section{Immunohistochemical and Immunofluorescent Staining}

Tissue samples were fixed with $0.1 \mathrm{~mol} / \mathrm{L}$ phosphate buffer $(\mathrm{pH} 7.4)$ containing $4 \%$ paraformaldehyde and were embedded in Tissue-Tek optimal cutting temperature compound (Sakura Finetek Japan, Tokyo, Japan). Serial cryostat sections (5 $\mu \mathrm{m}$ thick) were mounted on silanized slides (Dako, Tokyo, Japan). The specimens were immersed in a solution of $3 \% \mathrm{H}_{2} \mathrm{O}_{2}$ in absolute methanol to inhibit endogenous peroxidase activity for 5 minutes and then were incubated in 5\% nonfat milk for 10 minutes. A rabbit monoclonal anti-HMGB1 antibody (diluted 1:250; Abcam, Cambridge, MA), anti-phosphorylated-p38 (Santa Cruz Biotechnology, Santa Cruz, CA), anti-phosphorylated c-Jun N-terminal kinase (JNK) (Cell Signaling Technology, Danvers, MA), and anti-phosphorylated-ERK (Santa Cruz Biotechnology) were applied as the primary antibodies and were incubated overnight at $4^{\circ} \mathrm{C}$ with the specimens. A Histofine Simple Stain MAX peroxidase kit (Nichirei Biosciences, Tokyo, Japan) was used as the secondary antibody, incubated with the specimens for 1 hour according to the manufacturer's instructions. Immunoreactivity was visualized by treating the sections with a Histofine Simple Stain diaminobenzidine solution (Nichirei Biosciences). The specimens were then counterstained with hematoxylin. H\&E staining was performed for morphological observations.

Expression levels of TLR2, TLR4, and RAGE and the colocalization of these receptors with leukocytes or endothelial cells were determined with an immunofluorescence method. The primary antibodies used in the immunofluorescent staining were as follows (all diluted 1:200; Abcam): mouse monoclonal antibodies against TLR2 and TLR4, a rat monoclonal antibody against RAGE, rabbit monoclonal antibodies against CD68 (a monocyte/macrophage marker) and CD3, and a rabbit polyclonal antibody against CD31 (a marker of endothelial cells). The tissue samples, prepared as described above, were incubated overnight at $4^{\circ} \mathrm{C}$ with the primary antibodies and then reacted with the corresponding secondary fluores- cent dye-conjugated antibodies (Alexa Fluor 488 and 594; Invitrogen, Carlsbad, CA) for 2 hours. Samples were examined under a confocal microscope equipped with argon and argon-krypton laser sources.

\section{Histological Evaluation of Small Intestinal Damage}

Tissue sections stained with H\&E were viewed under a light microscope. For each mouse, at least 10 random villi at injured areas were scored in a masked fashion by two investigators independently (Y.N and T.W). For evaluation, we used a modified histological scoring system. ${ }^{22,23}$ The histology score ranged from 0 to 13 and was subdivided into the following six categories: epithelium $(0=$ normal, 1 = flattened, 2 = loss of epithelial continuity, $3=$ severe denudation), villus shape $(0=$ normal, $1=$ short and rounded, 2 = extremely short and thick), villus tip $(0=$ normal, $1=$ damaged, $2=$ severely damaged $)$, stroma $(0=$ normal, $1=$ slightly retracted, $2=$ severely retracted), inflammation $(0=$ no infiltration, $1=$ mild infiltration, 2 = severe infiltration), and crypt status ( $0=$ normal, 1 = mild crypt loss, 2 = severe crypt loss).

\section{Measurement of Serum HMGB1 Levels}

Blood samples (1000 $\mu \mathrm{L}$ ) were obtained in serum separator tubes by cardiac puncture. After centrifugation at $780 \times g$ for 10 minutes, the serum was collected and stored at $-80^{\circ} \mathrm{C}$. Serum levels of HMGB1 were measured using an HMGB1 sandwich ELISA kit (Shino-Test) according to the manufacturer's protocol.

\section{Nuclear Protein Extraction and Determination of Signal Transduction Activity of NF- $\kappa B$}

Mice received intraperitoneal injections of rHMG1 (1000 $\mu \mathrm{g} / \mathrm{kg}$ ), neutralizing chicken anti-HMGB1 polyclonal antibody $(50 \mathrm{mg} / \mathrm{kg}$ ), or vehicle at 0 and 3 hours after treatment with $10 \mathrm{mg} / \mathrm{kg}$ of indomethacin and were sacrificed 3 hours after the indomethacin challenge. The 
small intestinal tissues of the mice were assayed for $\mathrm{NF}-\kappa \mathrm{B}$ activation. Nuclear proteins of the small intestine were extracted using an NE-PER nuclear protein extraction kit (Thermo Fisher Scientific, Rockford, IL). Binding activity of the NF- $\kappa$ B p65 subunit to the NF- $\kappa$ B DNAbinding consensus sequence 5'-GGGACTTTCC-3' was measured using an ELISA-based transcription factor activation assay kit (TransAM; Active Motif, Carlsbad, CA) according to the manufacturer's instructions. The kit uses a 96-well microtiter plate that is coated with an oligonucleotide containing the NF- $\kappa \mathrm{B}$ consensus sequence. After incubation with an antibody to p65, a horseradish peroxidase-conjugated secondary antibody was added, followed by addition of a developing solution. Absorbance was read on a spectrophotometer (MTP-500; Corona Electronics, Ibaraki, Japan) at $450 \mathrm{~nm}$ with a reference wavelength of $655 \mathrm{~nm}$ on a spectrophotometer.

\section{Western Blotting}

Small intestinal tissues were homogenized and lysed on ice in a buffer containing 0.5\% NP-40, 40 mmol/L Tris- $\mathrm{HCl}$ (pH 8.0), $120 \mathrm{mmol} / \mathrm{L} \mathrm{NaCl}$, phosphatase inhibitor cocktail (PhosSTOP; Roche Applied Science, Indianapolis, IN), and a Complete Mini protease cocktail inhibitor (Thermo Fisher Scientific). Protein levels in the lysate were measured with a modified bicinchoninic acid method (Thermo Fisher Scientific). Proteins were denatured with sample buffer at $95^{\circ} \mathrm{C}$ for 5 minutes, subjected to $10 \%$ SDS-PAGE, and transferred to a polyvinylidene difluoride membrane. Membranes were blocked in Trisbuffered saline buffer $(10 \mathrm{mmol} / \mathrm{L}$ Tris- $\mathrm{HCl} \mathrm{pH}$ 7.5, 100 $\mathrm{mmol} / \mathrm{L} \mathrm{NaCl}, 0.1 \%$ Tween-20) containing 5\% nonfat milk and then were incubated overnight with one of the follow- ing antibodies: anti-phosphorylated-p38, anti-p38, antiphosphorylated JNK (Cell Signaling Technology), antiJNK, anti-phosphorylated-ERK, or anti-ERK (Santa Cruz Biotechnology). Bound antigen-antibody complexes were detected with anti-rabbit IgG-HRP with Amersham enhanced chemiluminescence (GE Healthcare Life Sciences, Arlington Heights, IL) according to the manufacturer's instructions. Relevant bands were quantified with laser-scanning densitometry.

\section{Statistical Analysis}

Data are expressed as means \pm SEM. One-way analysis of variance was used to test for significance of differences among treatment group means, and the results were analyzed with Fisher's protected least significant difference test. $P$ values of $<0.05$ were considered significant.

\section{Results}

\section{Small Intestinal Damage after NSAID Administration}

Macroscopic small intestinal damage, visualized as dark blue staining with 1\% Evans Blue (Figure 1, A and B), was observed beginning 3 hours after indomethacin administration. The lesion index increased in a time-dependent manner (Figure 1C). Similarly, naproxen induced small intestinal damage (Figure 1C), whereas administration of NS-398 did not cause small intestinal injury. mRNA expression levels for TNF- $\alpha, \mathrm{KC}$, and MCP- 1 increased after indomethacin administration (Figure 1, D-F).
A
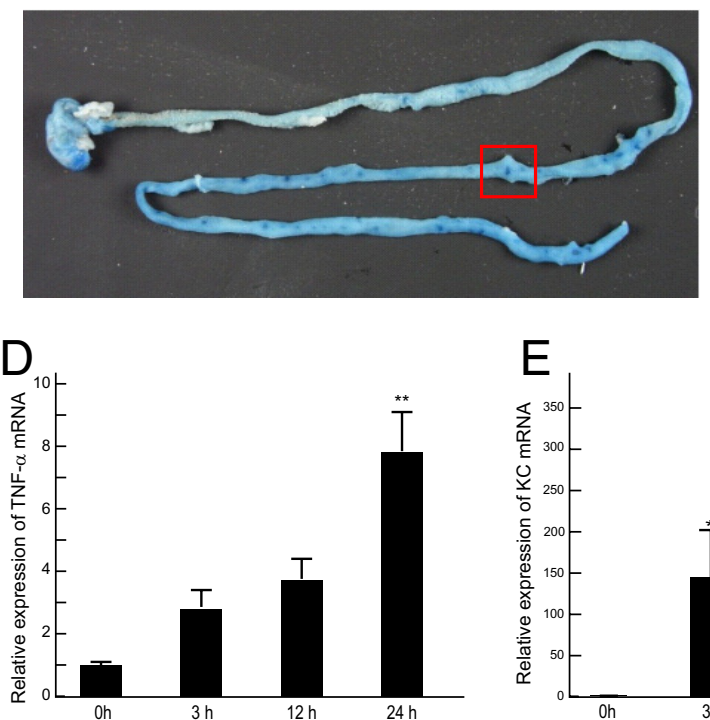
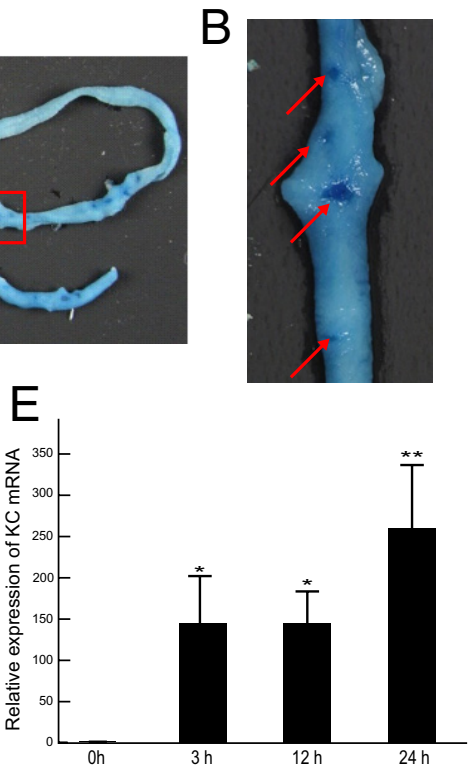
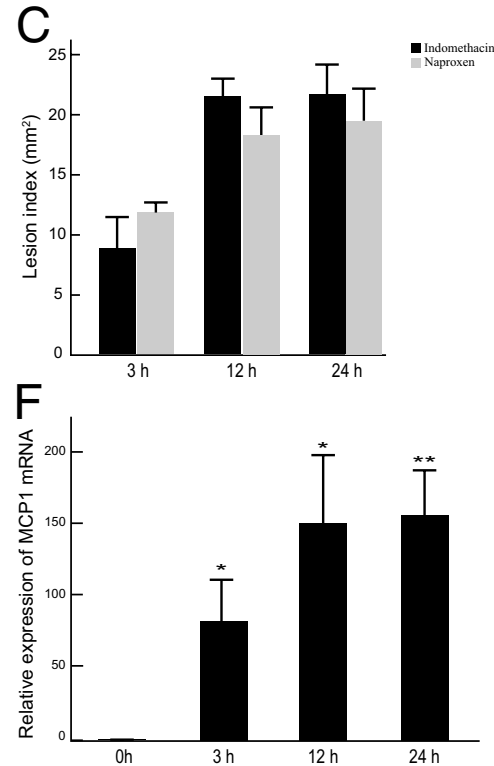

Figure 1. Small intestinal damage and cytokine expression after NSAID administration. A: Injured mucosa stained dark blue (1\% Evans Blue stain). B: Enlarged, rotated view of mucosa injury (arrows), relative to the boxed area in $\mathbf{A}$. C: Time course of lesion index after administration of indomethacin and naproxen. The areas of the macroscopically visible lesions, stained with Evans Blue, were measured and summed per small intestine to yield the lesion index. D, E, and F: mRNA expression levels of TNF- $\alpha$, mouse IL- 8 homolog keratinocyte chemoattractant (KC), and monocyte chemotactic protein-1 (MCP-1), respectively, were determined by quantitative reverse transcription-polymerase chain reaction (RT-PCR), relative to the mean value for normal small intestinal tissue. Data are expressed as means \pm SEM. $n=5$ or $6(\mathbf{C}) ; n=6(\mathbf{D}, \mathbf{E}$, and $\mathbf{F}) .{ }^{*} P<0.05,{ }^{* *} P<0.01$ versus untreated controls. 

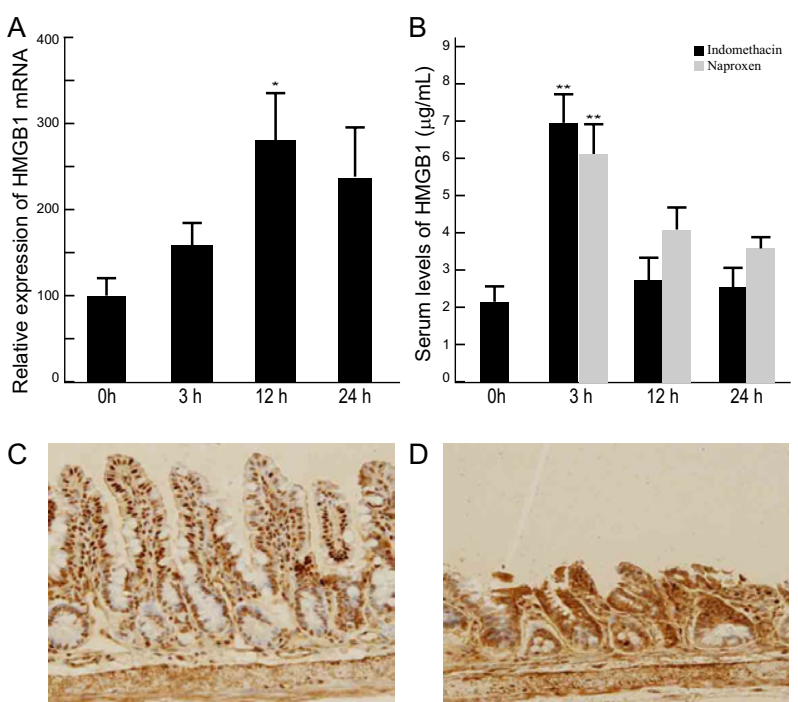

Figure 2. HMGB1 expression in small intestinal tissue after NSAID administration. Changes in HMGB1 mRNA expression levels (A), relative to control (0 hour), and changes in HMGB1 serum levels (B) during development of NSAIDinduced small intestinal injury. HMGB1 mRNA expression levels were determined by quantitative RT-PCR and serum levels of HMGB1 were determined by ELISA. C and D: Immunohistochemistry for HMGB1 in small intestinal tissue. In normal intestinal mucosa (C), localization of HMGB1 was limited to the nuclei of the epithelial cells and interstitial cells in normal intestinal mucosa. Indomethacin treatment induced prominent cytoplasmic staining of HMGB1 in epithelial cells (D) at the injured area by 3 hours. Original magnification, $\times 100$. Data are expressed as means \pm SEM. $n=5-8 .{ }^{*} P<0.05$, ${ }^{* * *} P<0.01$ versus control group.

\section{HMGB1 Expression after NSAID Administration}

mRNA levels for HMGB1 in the small intestine peaked 12 hours after indomethacin administration (Figure 2A), and serum levels of HMGB1 peaked by 3 hours (Figure 2B). Similar dynamics of serum HMGB1 levels were observed in the naproxen-treated mice. The administration of NS398, however, did not affect serum levels of HMGB1.

Immunohistochemically, HMGB1 localization was limited to inside the nuclei of epithelial cells and interstitial cells in normal intestinal mucosa (Figure 2C). In injured areas, however, indomethacin treatment induced prominent cytoplasmic staining of HMGB1 in epithelial cells by 3 hours (Figure 2D).

\section{Effects of Exogenous HMGB1, the Immunoneutralizing of HMGB1, and the Inhibition of HMGB1 Release on Indomethacin- Induced Small Intestinal Injury}

The administration of rHMGB1 at a dose of $1000 \mu \mathrm{g} / \mathrm{kg}$ significantly aggravated small intestinal damage and increased mRNA expression levels for TNF- $\alpha, \mathrm{KC}$, and MCP-1 by 24 hours (Figure 3, A-E). In contrast, neutralizing antibodies to HMGB1 prevented the damage by reducing $\mathrm{mRNA}$ expression levels of these inflammatory cytokines (Figure 3, F-J). Furthermore, the administration of ethyl pyruvate, which is an inhibitor of HMGB1 release, markedly inhibited the indomethacin-induced small intestinal damage (by 55.0\%) and inhibited mRNA expression levels for TNF- $\alpha, \mathrm{KC}$, and MCP-1 by $17.6 \%, 70.9 \%$, and $45.4 \%$, respectively, 24 hours after the indomethacin challenge (data not shown).
Histologically, indomethacin caused intestinal sloughing and the destruction of the upper part of the epithelium and the infiltration of inflammatory cells by 3 hours (Figure 4A). By 12 hours, these mucosal injuries had progressed, and necrosis and destruction of the lower part of the epithelium were observed. By 24 hours, the intestinal ulcers extended into the submucosal layer, with a massive infiltration of inflammatory cells (Figure 4, B and C).

In the rHMGB1-treated group, indomethacin caused more severe injuries by 3 hours, with more destructive and necrotic changes of the epithelium and inflammatory cell infiltration (Figure 4D) compared with the vehicle-treated group, whereas it caused less severe injuries in the antiHMGB1 antibody-treated group (Figure 4E). Similarly, the mean histological score was significantly higher in the rHMGB1-treated group after 24 hours (Figure 4F), compared with the vehicle-treated group, whereas it was lower in the anti-HMGB1 antibody-treated group (Figure 4G).

\section{Activation of Intracellular Signal Transduction in Indomethacin-Induced Small Intestinal Injury}

Indomethacin increased the binding activity of NF- $\kappa \mathrm{B}$ by 3 hours in the small intestine, an increase that was further enhanced by exogenous HMGB1 (Figure 5A). The neutralizing antibody to HMGB1 prevented the increase in NF- $\kappa \mathrm{B}$ binding activity by indomethacin (Figure 5B).

The indomethacin challenge induced the phosphorylation of p38, JNK, and ERK by 3 hours (Figure 5, C-E). Exogenous HMGB1 further increased the phosphorylation of p38 and JNK and generally increased the phosphorylation of ERK $(P=0.07)$ (Figure $5, \mathrm{~F}-\mathrm{H})$. In contrast, anti-HMGB1 antibodies inhibited the phosphorylation of the MAPKs that were induced by indomethacin treatment, although the differences in phosphorylation levels between the anti-HMGB1 antibody-treated groups and the control antibody-treated group were not significant (Figure 5, I-K).

Immunohistological analysis showed that phosphop38 and phospho-JNK were expressed mainly in the cytoplasm of inflammatory cells in the injured mucosa. The cytoplasm of some epithelial cells was also weakly stained for phospho-p38 and phospho-JNK. Treatment with rHMGB1 induced stronger nuclear staining in inflammatory cells than cytoplasmic staining in epithelial cells. Conversely, immunoneutralization of HMGB1 reduced expression in both inflammatory cells and epithelial cells (Figure 6, A-H). Expression of phospho-ERK was restricted almost exclusively to inflammatory cells. Treatment with rHMGB1 induced stronger staining in the nucleus and cytoplasm of inflammatory cells. Conversely, immunoneutralization of HMGB1 reduced expression in inflammatory cells (Figure 6, I-L).

\section{Role of TLR2, TLR4, and RAGE in Indomethacin-Induced Small Intestinal Injury}

TLR4 deficiency resulted in the inhibition of small intestinal injury and prevented the increase of TNF- $\alpha$ 
A
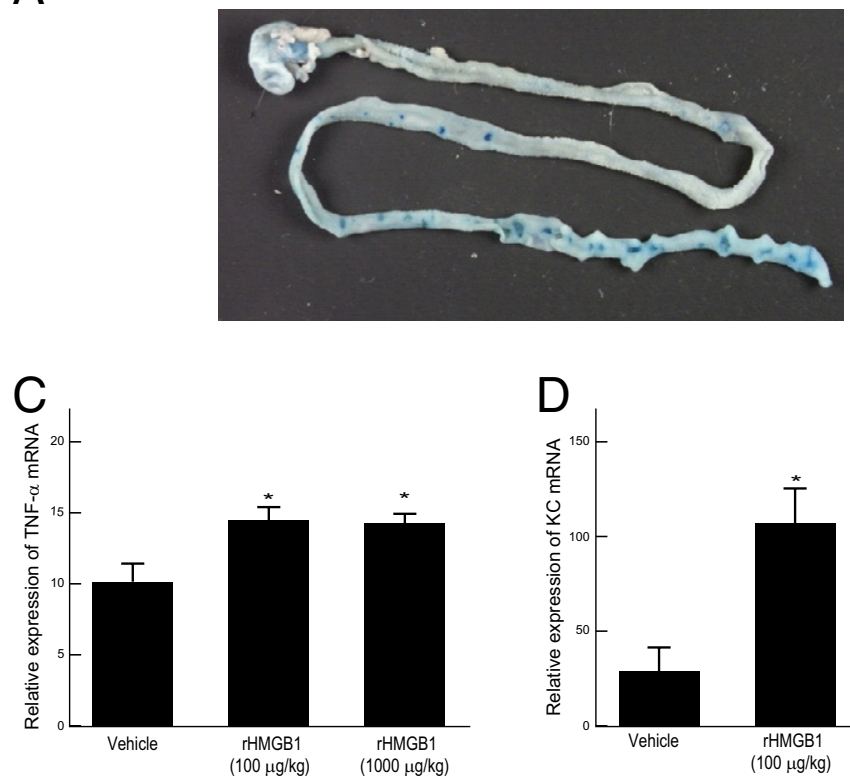

$\mathrm{F}$
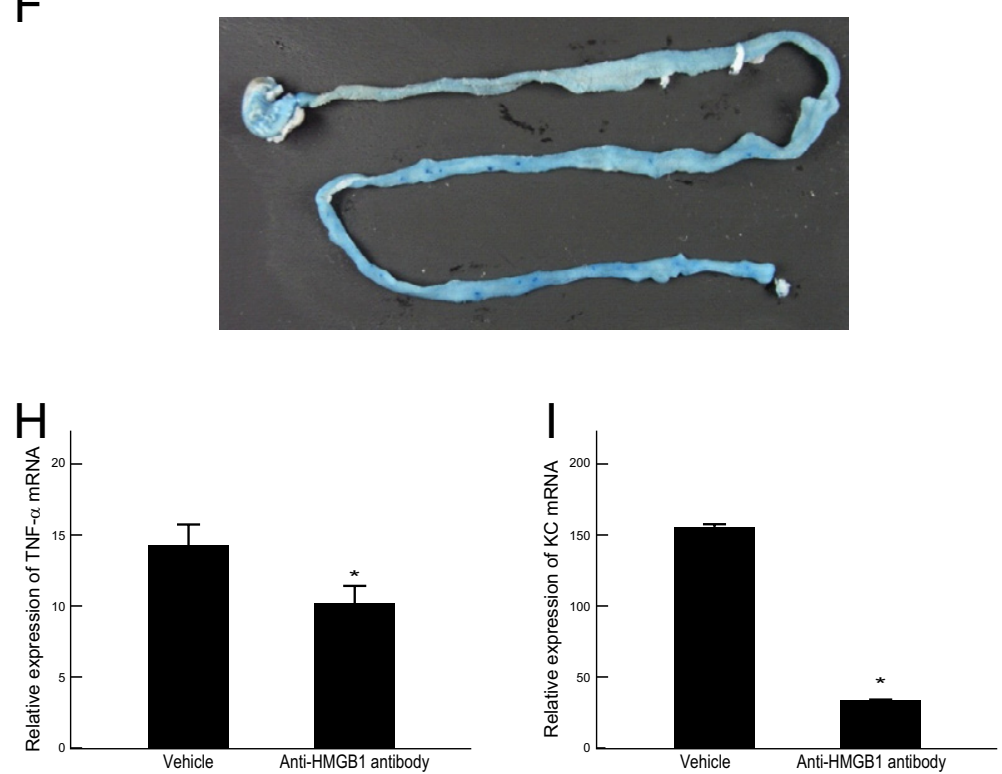

$\mathrm{B}$
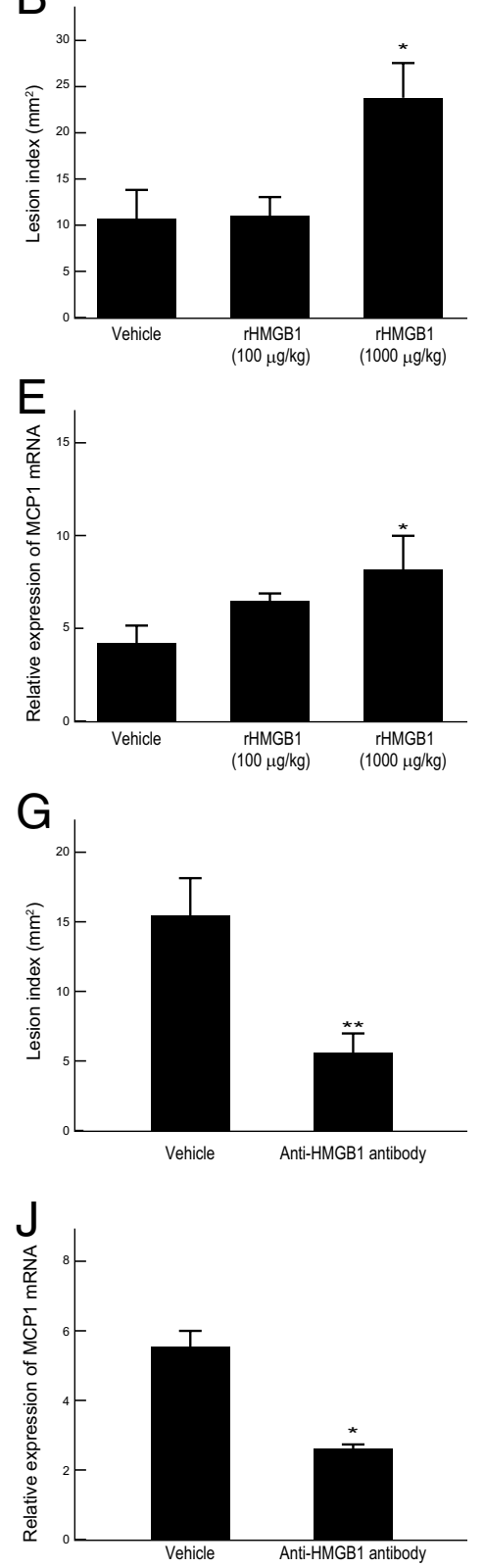

Figure 3. Effect of exogenous HMGB1 and immunoneutralizing of HMGB1 on the damage and cytokine expression in indomethacin-induced small intestinal injury. Mice received intraperitoneal injections of human rHMGB1 (100 to $1000 \mu \mathrm{g} / \mathrm{kg}$ ), neutralizing chicken anti-HMGB1 polyclonal antibody (50 mg/kg), or vehicle at 0 and 3 hours after indomethacin treatment and were sacrificed 24 hours after indomethacin challenge. Small intestinal tissues were subjected to area measurement for lesion index and quantification of cytokine mRNA expression. Macroscopically visible lesions stained dark (Evans Blue) in the $1000 \mathrm{mg} / \mathrm{kg}$ HMGB1-treated groups (A) and in the anti-HMGB1 polyclonal antibody-treated group (F). B-E: Effects of exogenous HMGB1 on the damage and cytokine expression in indomethacin-induced small intestinal injury. The areas of the macroscopically visible lesions were measured and summed per small intestine to yield the lesion index (B). mRNA expression levels of TNF- $\alpha(\mathbf{C}), \mathrm{KC}(\mathbf{D})$, and MCP-1 (E) were determined by quantitative RT-PCR. F-J: The effect of the anti-HMGB1 antibody on damage and cytokine expression in indomethacin-induced small intestinal injury. Lesion index $(\mathbf{G})$ and mRNA expression levels of TNF- $\alpha(\mathbf{H})$, KC (I), and MCP-1 (J) were determined as described for B-E. Data are expressed as means \pm SEM. $n=5$ or $6 .{ }^{* * *} P<0.01,{ }^{*} P<0.05$ versus vehicle-treated control group.

mRNA expression by 24 hours after indomethacin treatment (Figure 7, A and B), whereas neither TLR2 deficiency nor RAGE deficiency affected injury and expression of TNF- $\alpha$ mRNA (Figure 7, C-F). Exogenous HMGB1 aggravated small intestinal injury in both TLR2-KO and RAGE-KO mice and increased the mRNA expression levels of TNF- $\alpha$ in TLR2-KO mice, but did not affect injury and mRNA expression levels of TNF- $\alpha$ in TLR4-KO mice (Figure 7).
Histological examination revealed that indomethacin caused less severe injury in TLR4-KO mice, compared with wild-type mice (Figure 7, $\mathrm{G}$ and $\mathrm{H}$ ). Administration of $\mathrm{rHMGB} 1$ did not affect the severity of injury in TLR4-KO mice (Figure 7, $\mathrm{H}$ and I). The mean histological score was significantly lower in TLR4-KO mice, compared with wild-type mice. Treatment with rHMGB1 did not affect the histological score in TLR4 KO mice (Figure 7J). 
A

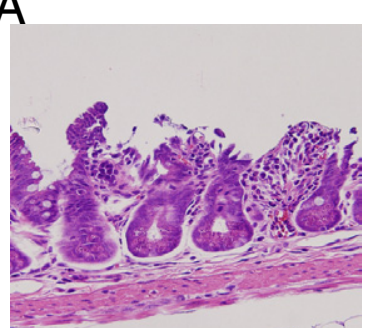

C

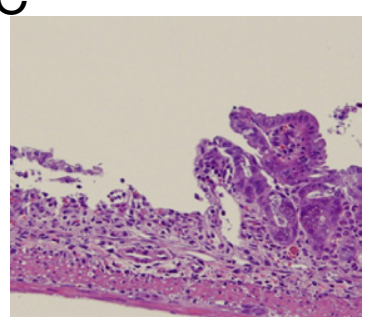

$E$
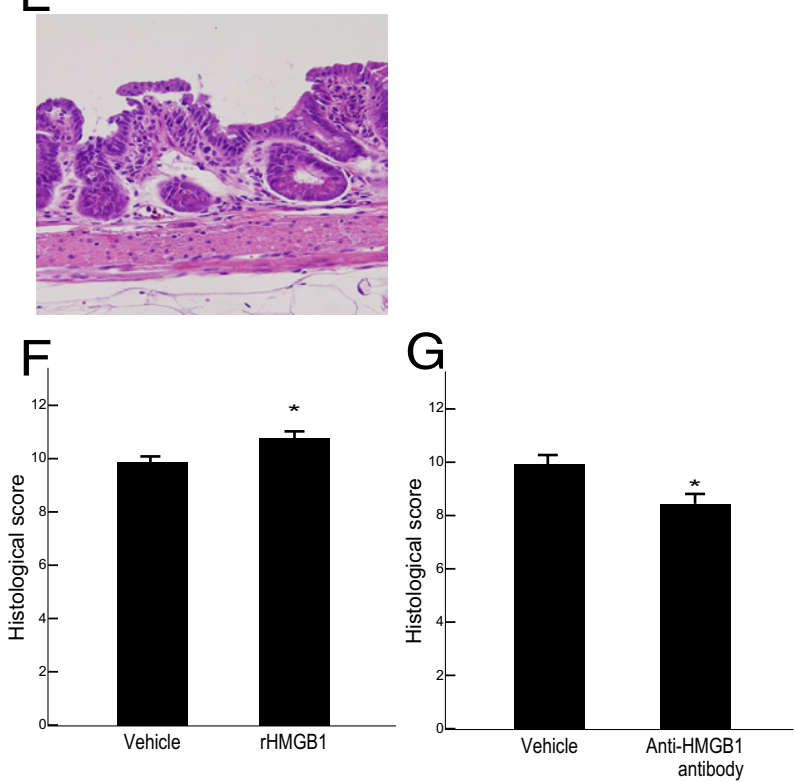

Figure 4. Histological findings of indomethacin-induced small intestinal injury. A: Indomethacin caused intestinal sloughing and destruction of the upper part of the epithelium with infiltration by inflammatory cells by 3 hours. B: By 24 hours, intestinal ulcers that extended into the submucosa layer with massive infiltration by inflammatory cells had developed. C: Higher magnification view relative to the boxed area in B. D: In the rHMGB1-treated group, indomethacin caused severe injuries with additional destructive and necrotic changes of the epithelium and inflammatory cell infiltration by 3 hours, compared with the vehicle-treated group. E: Indomethacin caused less severe injury by 3 hours in the anti-HMGB1 antibodytreated group, compared with the vehicle-treated group. $\mathbf{F}$ and $\mathbf{G}$ : Effect of rHMGB1 and anti-HMGB1 antibody on the severity of indomethacin-induced small intestinal injury. Intestinal damage was quantified by a histological scoring system on a scale of 0 to 13 . Data are expressed as means \pm SEM. ${ }^{*} P<0.05$ versus vehicle-treated control group. Original magnification, $\times 100$ (A. C-E); $\times 40(\mathbf{B})$

\section{Expression of TLR2, TLR4, and RAGE during Development of Indomethacin-Induced Small Intestinal Injury}

Indomethacin increased mRNA expression levels of TLR4 in a time-dependent manner, but did not affect expression of TLR2 or RAGE (Figure 8, A-C). Both TLR2 and TLR4 were expressed in inflammatory cells and in some epithelial cells in the small intestine (Figure 8, D, G, $\mathrm{J}$, and $\mathrm{M}$ ). The levels of expression of RAGE in the small intestine were very low, and the immunoreactivity of RAGE was limited to the surface of epithelial cells (Figure $8 \mathrm{~N})$. Immunohistochemical double staining showed that TLR4 was expressed on monocytes/macrophages and some $\mathrm{CD}^{+}$Iymphocytes, but was not expressed on vascular endothelial cells (Figure 8, D-L). Similarly, TLR2 was expressed on monocytes/macrophages and some $\mathrm{CD}^{+}$lymphocytes (data not shown).

\section{Discussion}

Several factors, including enterobacteria, inflammatory cytokines, bile, increased intestinal permeability, mitochondrial damage, and prostaglandin deficiency, ${ }^{24-26}$ have been reported to be involved in the pathogenesis of NSAID-induced enteropathy. In the present study, we demonstrated that immunoneutralizing HMGB1 and inhibiting HMGB1 release by ethyl pyruvate inhibited indomethacin-induced small intestinal injury by reducing the levels of expression of TNF- $\alpha$, whereas exogenous HMGB1 aggravated the injury and induced cytokine overexpression. Furthermore, a deficiency of TLR4, which is a receptor of HMGB1, prevented the injury and $\mathrm{TNF}-\alpha$ overexpression caused by indomethacin challenge, and exogenous HMGB1 failed to aggravate the injury in TLR4-KO mice. These results suggest that HMGB1 plays a critical role in NSAID-induced enteropathy through a TLR4-dependent pathway.

Wang et $\mathrm{al}^{9}$ demonstrated that extracellular HMGB1 promotes inflammation as an alarmin. HMGB1 aggravates a variety of pathophysiological conditions, including ischemia-reperfusion injury, hemorrhagic shock, and sepsis, in both human and animal models. 6,17,18,27-30 Under these conditions, at least three receptors (ie, TLR2, TLR4, and RAGE) have been reported to mediate the proinflammatory effects of HMGB1. In the present study, we found that, of these receptors, only TLR4 played a crucial role in NSAID-induced enteropathy, which is mediated by HMGB1. Consistent with our findings, many reports indicate the importance of TLR4 in HMGB1-mediated tissue injuries. Tsung et $\mathrm{al}^{17}$ demonstrated that HMGB1 is involved in hepatic I-R injury, with TLR4-deficient mice exhibiting less damage. Barsness et $\mathrm{al}^{29}$ demonstrated that TLR4 deficiency prevents hemorrhagic shock-induced lung injury, TNF- $\alpha$ expression, and neutrophil infiltration, and $\mathrm{Kim}$ et $\mathrm{al}^{30}$ demonstrated that HMGB1 participates in hemorrhage-induced acute lung injury. In vitro studies using macrophage cell lines indicated that TLR2 is an HMGB1 receptor. 6,12 However, in vivo effects of TLR2 in HMGB1-mediated pathologies have never been reported. Thus, the HMGB1/TLR2 pathway may play only a minor role in the pathogenesis of tissue injuries and inflammation.

Several reports indicate that HMGB1 plays an important role in the pathogenesis of tissue injuries in vivo through RAGE. Zeng et $\mathrm{al}^{31}$ demonstrated that blocking 
A

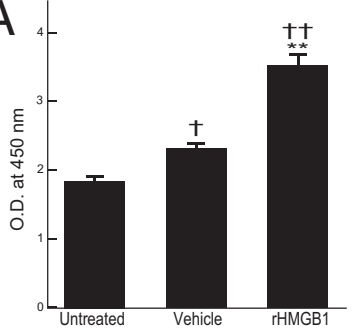

C
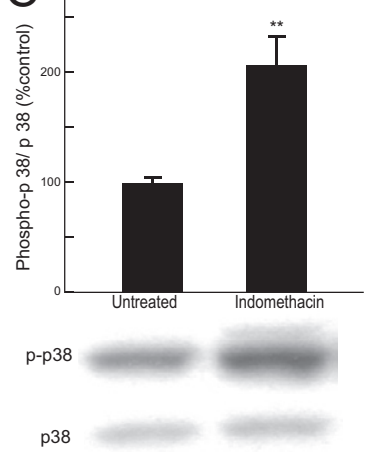

$\mathrm{F}$

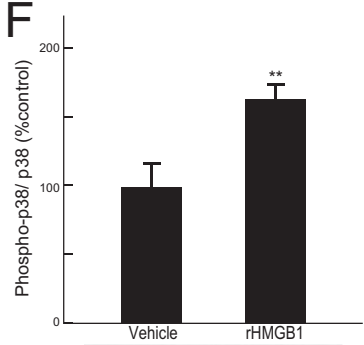

p-p38

p38

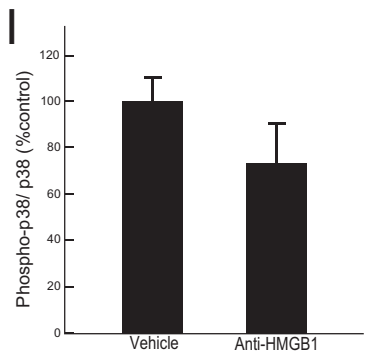

p-p38

p38
B

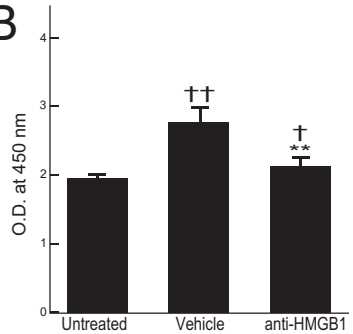

D
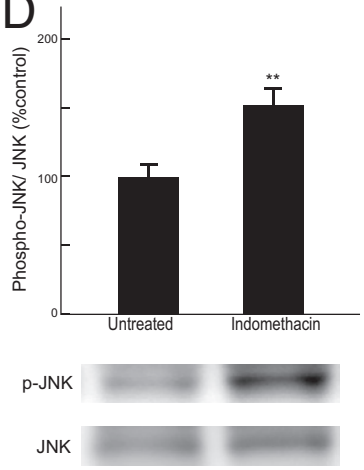

G
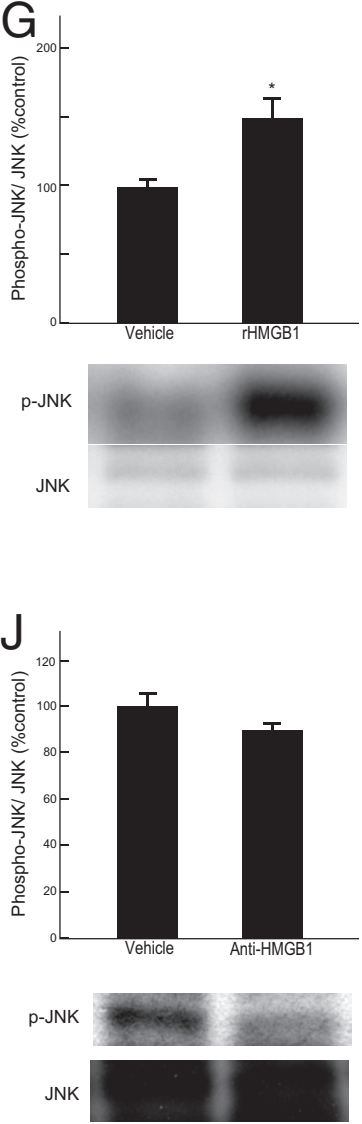
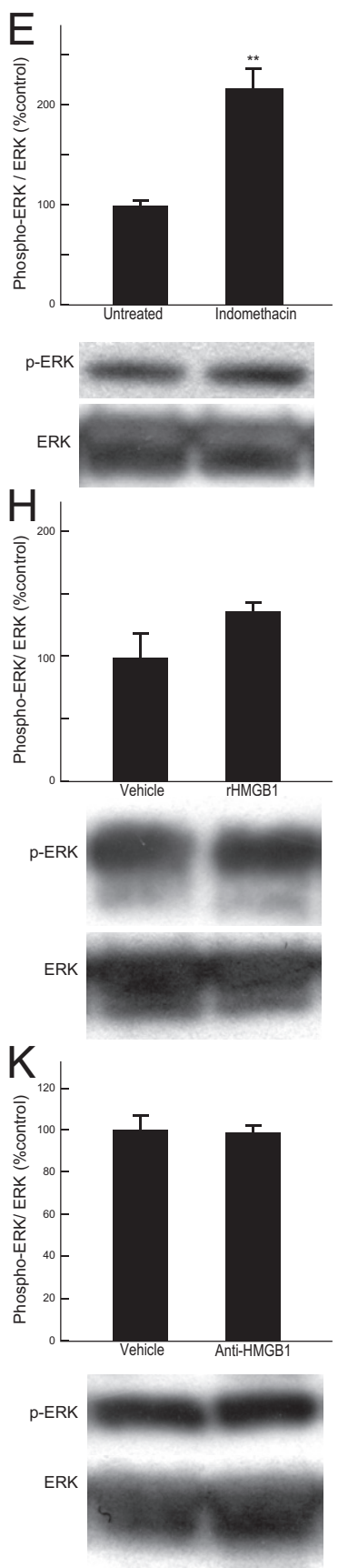

Figure 5. Activation of signal transduction in indomethacin-induced small intestinal injury. Mice received intraperitoneal injections of human rHMGB1 (1000 $\mu \mathrm{g} / \mathrm{kg})$, neutralizing chicken anti-HMGB1 polyclonal antibody $(50 \mathrm{mg} / \mathrm{kg})$, or vehicle at 0 and 3 hours after indomethacin treatment and were sacrificed 3 hours after indomethacin challenge. The binding activity of NF- $\kappa \mathrm{B}$ was assayed using an ELISA-based NF- $\kappa \mathrm{B}$ p 65 kit; the phosphorylation levels of MAPKs p38, JNK, and ERK were evaluated by Western blotting. A: Effect of exogenous HMGB1 on NF- $\kappa$ B binding activity. B: Effect of neutralizing antibody to HMGB1 on NF- $\kappa$ B binding activity. C-K: Representative Western blot for phospho-p38, total p38, phospho-JNK, total JNK, phospho-ERK, and total ERK, respectively. Expression levels of phospho-p38, phospho-JNK, and phospho-ERK were normalized to those of total p38, total JNK, and total ERK, respectively. Data are expressed as means \pm SEM. $n=7$ or $8(\mathbf{A}) ; n=8(\mathbf{B}) ; n=4$ or $5(\mathbf{C}-\mathbf{K}) .{ }^{*} P<0.05,{ }^{* * *} P<0.01$ versus vehicle-treated control group; ${ }^{\dagger} P<0.05,{ }^{t} P<0.01$ versus untreated group (A). ${ }^{*} P<0.05,{ }^{* * *} P<0.01$ versus irrelevant antibody-treated control group; ${ }^{\dagger} P<0.05,{ }^{\dagger} P<0.01$ versus untreated group $(\mathbf{B})$. ${ }^{*} P<0.05$, ${ }^{* *} P<0.01$ versus vehicle-treated control group (C-K). O.D., optical density. 

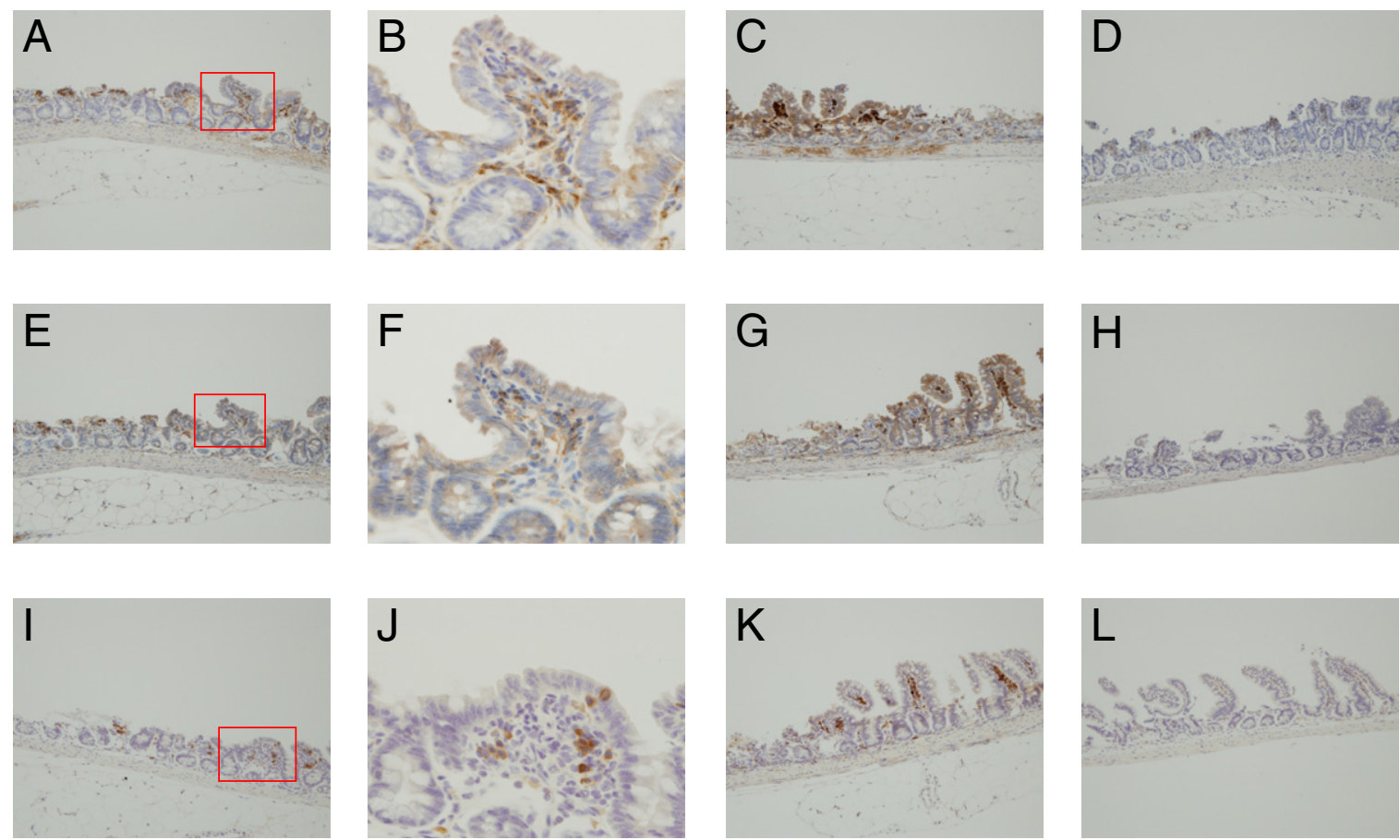

Figure 6. Expression of phospho-p38, phospho-JNK, and ERK in indomethacin-induced small intestinal injury. Mice received intraperitoneal injections of human rHMGB1 $(1000 \mu \mathrm{g} / \mathrm{kg})(\mathbf{C}, \mathbf{G}$, and $\mathbf{K})$, neutralizing chicken anti-HMGB1 polyclonal antibody $(50 \mathrm{mg} / \mathrm{kg})(\mathbf{D}, \mathbf{H}$, and $\mathbf{L})$, or vehicle $(\mathbf{A}$ and $\mathbf{B}, \mathbf{E}$ and $\mathbf{F}, \mathbf{I}$ and $\mathbf{J})$ at 0 and 3 hours after indomethacin treatment and were sacrificed 3 hours after indomethacin challenge. Phospho-p38 (A-D) and phospho-JNK (E-H) were expressed mainly in the cytoplasm of inflammatory cells in the injured mucosa. The cytoplasm of some epithelial cells was also weakly stained for phospho-p38 and phospho-JNK. Treatment with rHMGB1 induced stronger nuclear staining in inflammatory cells than cytoplasmic staining in epithelial cells. Conversely, immunoneutralization of HMGB1 reduced the expression in both inflammatory cells and epithelial cells. Expression of phospho-ERK (I-L) was restricted almost exclusively to inflammatory cells. Treatment with rHMGB1 induced stronger staining in the nucleus and cytoplasm of inflammatory cells. Conversely, immunoneutralization of HMGB1 reduced the expression in inflammatory cells. Original magnification, $\times 100(\mathbf{A}, \mathbf{C}-\mathbf{E}, \mathbf{G}-\mathbf{I}, \mathbf{K}, \mathbf{L}) ; \times 400(\mathbf{B}, \mathbf{F}, \mathbf{J})$. B, F, and $\mathbf{J}$ : Higher magnification view relative to $\mathbf{A}, \mathbf{E}$, and $\mathbf{I}$, respectively.

RAGE is highly protective against hepatocellular death and necrosis in hepatic I-R injury. In a model of cardiac $\mathrm{I}-\mathrm{R}$ injury, Andrassy et $\mathrm{al}^{18}$ found that RAGE-deficient mice exhibited less damage. Notably, in the present study, RAGE deficiency did not protect against indomethacin-induced small intestinal damage. We demonstrated that expression of RAGE was very weak in the small intestine, whereas expression of TLR2 and TLR4 was abundant, suggesting that a lack of resistance to NSAID-induced small intestinal damage in RAGE-KO mice may be due to be a low level of RAGE expression.

According to a number of in vitro studies, a HMGB1TLR4 interaction leads to activation of NF- $\kappa \mathrm{B}$ and the MAPKs p38, JNK, and ERK in inflammatory cells, such as neutrophils and macrophages, ${ }^{8,14,32,33}$ through MyD88dependent signal pathways. ${ }^{27}$ This results in the induction of expression of inflammatory cytokines, including TNF- $\alpha$. The activation of MAPKs through the HMGB1TLR4 signaling pathway has been reported in several models of tissue injuries. HMGB1 stimulates the phosphorylation of p38 and JNK in I-R liver injury ${ }^{17}$ and of ERK in I-R myocardial injury. ${ }^{18}$ Nonetheless, reports of the effects of stimulating the HMGB1-TLR4 signaling pathway on NF- $\kappa \mathrm{B}$ activation are conflicting and inconclusive. Blocking HMGB1 activity using anti-HMGB1 antibodies diminished increases in nuclear translocation of $\mathrm{NF}-\kappa \mathrm{B}$ and diminished expression of inflammatory cytokines in acute lung injury after hemorrhage, ${ }^{30}$ which is TLR4-de- pendent, ${ }^{29}$ whereas blocking the HMGB1-TLR4 signaling pathway with anti-HMGB1 antibodies promoted NF- $\kappa \mathrm{B}$ DNA binding in liver I-R injury. ${ }^{17}$ Thus, the role of HMGB1 signaling in NF- $\kappa \mathrm{B}$ activation may differ, depending on the type of tissue injury.

In the present study, we demonstrated that both NF- $\kappa \mathrm{B}$ and MAPKs were activated during the early phase of indomethacin-induced small intestinal damage, and exogenous HMGB1 further increased activation levels and TNF- $\alpha$ expression. Moreover, immunoneutralization of HMGB1 prevented activation of NF- $\mathrm{B}$ and MAPKs. Together with the finding that TLR4 is expressed primarily in monocytes/macrophages in indomethacin-induced small intestinal injury, and that strong expression of phosphoMAPKs was observed in inflammatory cells after indomethacin challenge, these results suggest that activation of NF- $\kappa \mathrm{B}$ and MAPKs in monocytes/macrophages may play a crucial role in the aggravation of NSAID-induced enteropathy by inducing inflammatory cytokines.

In addition to the direct proinflammatory effects of HMGB1 through TLR4, HMGB1 can form a complex with inflammatory mediators and strongly enhance inflammation. Youn et $\mathrm{al}^{34}$ reported that HMGB1 can bind to LPS and facilitate the transfer of LPS to CD14 to enhance LPS-induced TNF- $\alpha$ production in human monocytes. Moreover, impairment of epithelial function by HMGB1 has been reported. HMGB1 inhibited enterocyte migration in a macrophage-enterocyte coculture system in a 
A

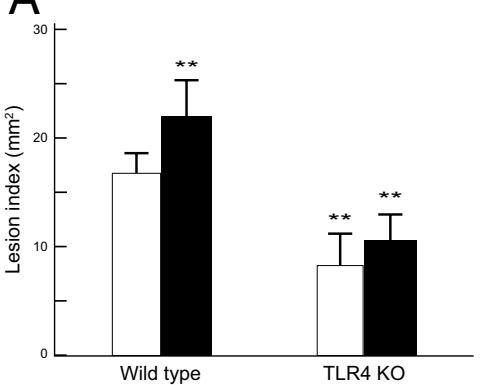

$\mathrm{D}$
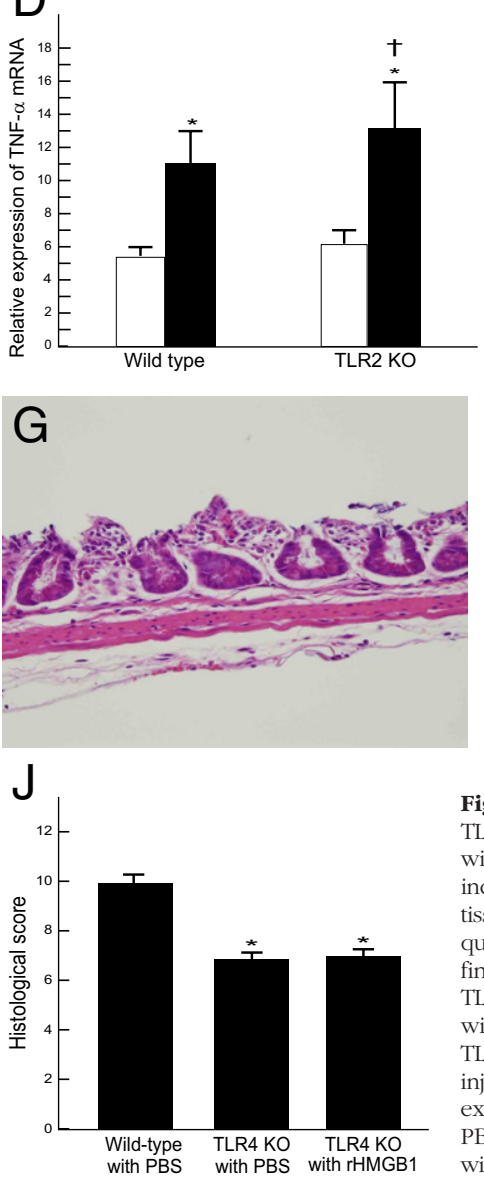

B

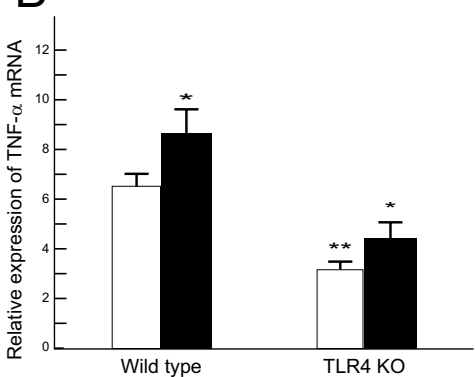

$E$
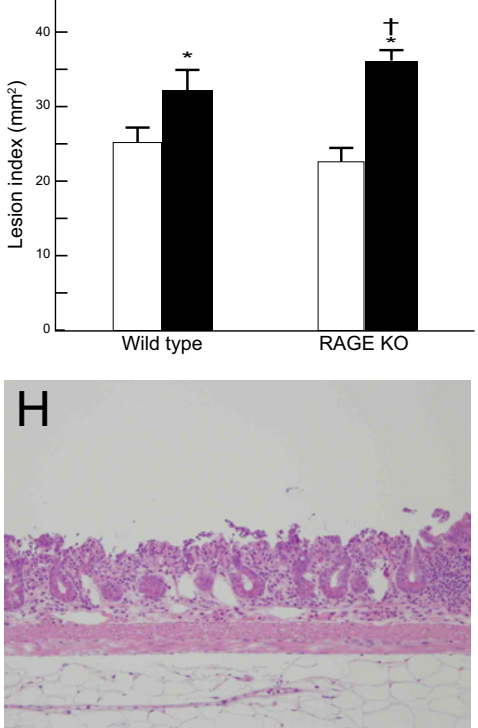

C

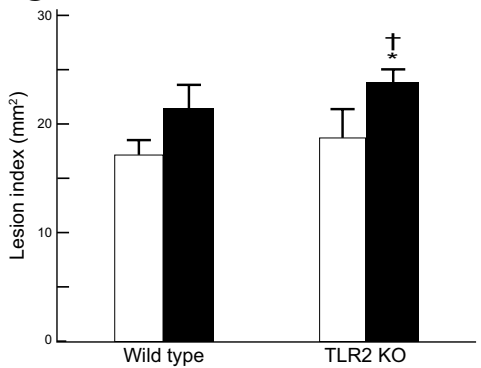

$\mathrm{F}$
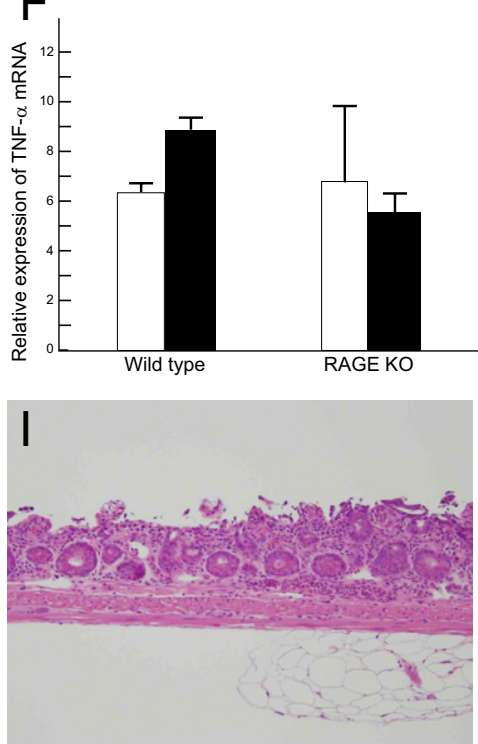

Figure 7. Role of TLR2, TLR4, and RAGE in indomethacin-induced small intestinal injury by 24 hours. TLR2-KO, TLR4-KO, and RAGE-KO mice were administered $10 \mathrm{mg} / \mathrm{kg}$ indomethacin by gavage with or without intraperitoneal injections of $1000 \mu \mathrm{g} / \mathrm{kg}$ rHMGB1. The mice were sacrificed 24 hours after indomethacin challenge. White bars, PBS; black bars, rHMGB1 (A-F). A, C, and E: Areas of small intestinal tissue injury were measured and summed to yield the lesion index. B, D, and F: TNF- $\alpha$ mRNA levels were quantified by RT-PCR, relative to the mean value for normal small intestinal tissue. G-I: Histological findings of indomethacin-induced small intestinal injury in wild-type mice (G), TLR4-KO mice (H), and TLR4-KO mice with rHMGB1 (I). Indomethacin caused less severe injury in TLR4-KO mice than in wild-type mice ( $\mathbf{G}$ versus $\mathbf{H}$ ). Administration of rHMGB1 did not influence the severity of the injury in TLR4-KO mice ( $\mathbf{H}$ versus $\mathbf{I}$ ). J: Effect of rHMGB1 on the severity of indomethacin-induced small intestinal injury. Intestinal damage was quantified by a histological scoring system on a scale of 0 to 13 . Data are expressed as means \pm SEM. $n=4-6(\mathbf{A}-\mathbf{F}) ; n=200(\mathbf{J})$. ${ }^{*} P<0.05$, ${ }^{* * k} P<0.01$ versus wild-type PBS-treated control; ${ }^{\dagger} P<0.05$ versus vehicle-treated KO mouse group $(\mathbf{A}-\mathbf{F}) .{ }^{*} P<0.05$ versus vehicle-treated wild-type mice $(\mathbf{J})$. Original magnification, $\times 100$.

TLR4-dependent manner, ${ }^{35}$ increased the permeability of Caco-2 monolayers to fluorescein isothiocyanate-labeled dextran in a time- and dose-dependent manner, ${ }^{36}$ and modulated bile-induced gut hyperpermeability and bacterial translocation in rats. ${ }^{37}$ These effects of HMGB1 may also be involved in the deterioration of indomethacin-induced enteropathy.

Necrotic or damaged cells, but not apoptotic cells, passively release HMGB1 ${ }^{38}$ whereas HMGB1 is actively secreted by activated monocytes and macrophages during inflammation. ${ }^{9}$ In the present study, serum HMGB1 levels were significantly elevated at 3 hours after indomethacin challenge, whereas HMGB1 mRNA expression was not increased. Because prominent cytoplasmic staining of HMGB1 in epithelial cells was observed in injured areas by 3 hours, this increase in serum HMGB1 levels may be due to the release of HMGB1 from epithelial cells. We also found that naproxen induced small intestinal damage along with elevation of serum HMGB1 levels, whereas NS-398, a selective cyclooxygenase inhibitor, failed to induce such damage or to affect serum HMGB1 levels. These results provide collateral evidence that the elevation of serum HMGB1 is due to the small intestinal damage induced by the ulcerogenic effect of NSAIDs, and not due to other effects.

Notably, the mRNA expression levels of HMGB1 were increased by 12 hours, but serum levels of HMGB1 reached a peak at 3 hours and then gradually decreased during the development of small intestinal injury. The cell-surface glycoprotein thrombomodulin can bind to HMGB1 through its lectin domain ${ }^{39}$ and can suppress the inflammatory response by preventing HMGB1 from inter- 
A

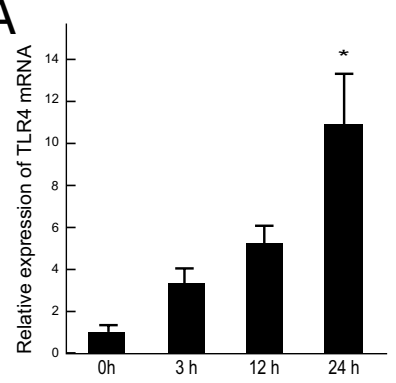

D

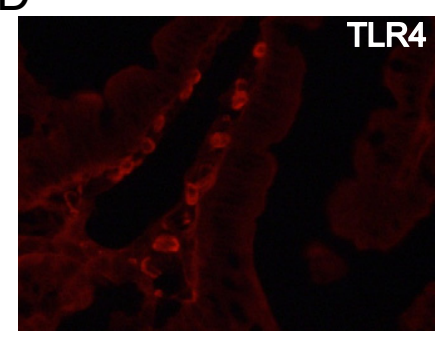

G

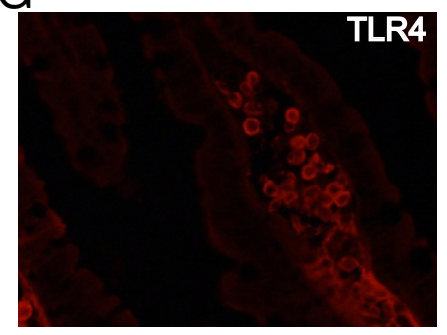

J

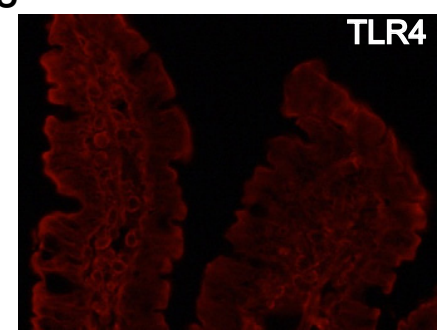

M

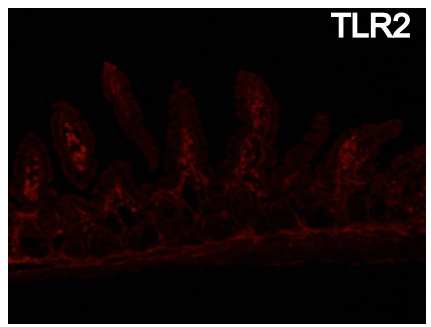

B

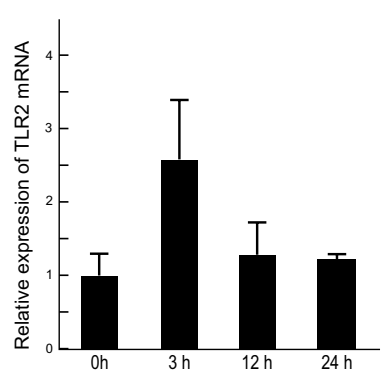

E

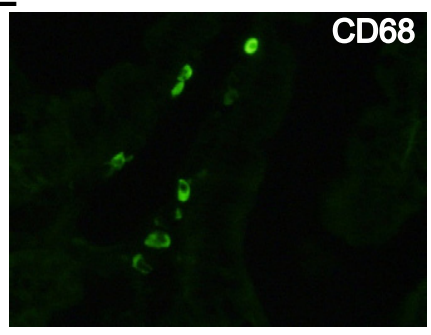

$\mathrm{H}$

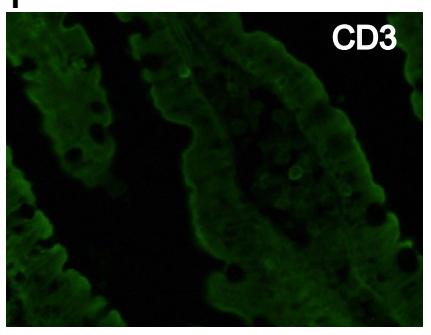

K

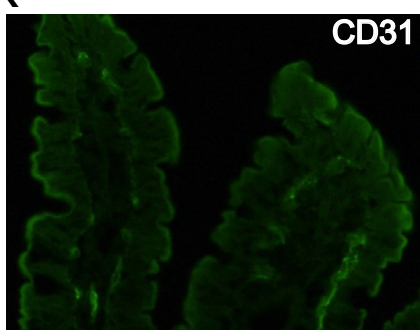

$\mathrm{N}$

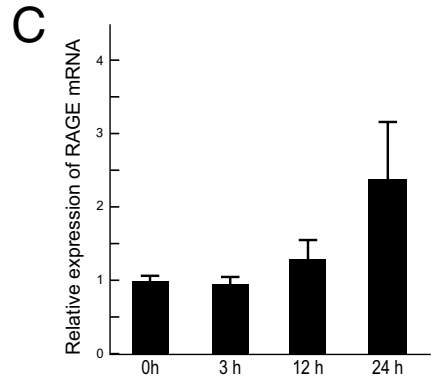

$\mathrm{F}$

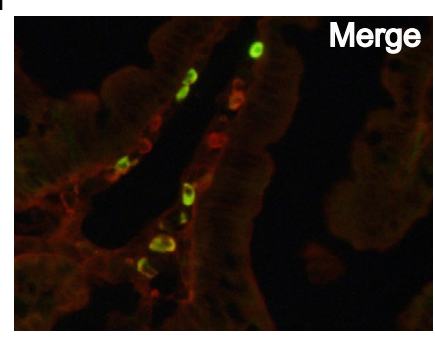

I

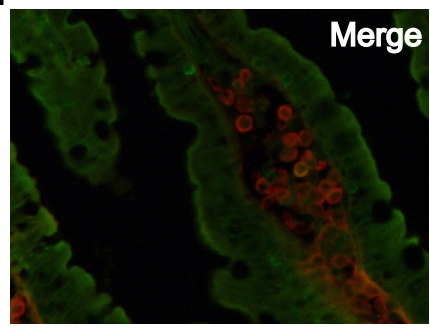

L

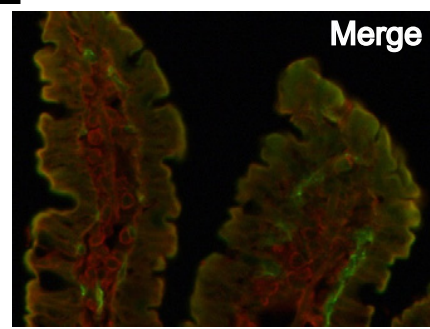

Figure 8. Expression of TLR2, TLR4, and RAGE during the development of indomethacin-induced small intestinal injury. Mice were administered 10 mg/kg of indomethacin and were sacrificed after 3, 12, or 24 hours. A-C: mRNA expression levels of TLR4 (A), TLR2 (B), and RAGE (C) were determined by quantitative RT-PCR, relative to the mean value for normal small intestinal tissue. D-L: Immunohistochemical double staining of TLR4 and monocytes/macrophages, CD ${ }^{+}$ lymphocytes, and vascular endothelial cells in the small intestinal tissue after indomethacin challenge. TLR 4 is expressed in inflammatory cells and some epithelial cells in the small intestine. The primary antibodies used in immunohistochemical double staining were mouse monoclonal antibodies against TLR4, as well as rabbit monoclonal antibodies against CD68, which is a marker of monocyte/macrophages (D-F), rabbit monoclonal antibodies againstCD3 (G-I), and rabbit polyclonal antibody against CD31, which is a marker of endothelial cells (J-L). Immunohistochemical double staining showed that TLR4 is expressed on many monocytes/macrophages and some $\mathrm{CD}^{+}$lymphocytes, but is not expressed on vascular endothelial cells. M and $\mathbf{N}$ : Immunohistochemistry for TLR2 and RAGE in small intestinal tissue. TLR2 and RAGE are expressed in inflammatory cells and some epithelial cells in the small intestine. The levels of expression of RAGE in the small intestine are very low, and the immunoreactivity of RAGE is limited to the surface of epithelial cells. Data are expressed as means \pm SEM. $n=6$ (A-C). Original magnification, $\times 400(\mathbf{D}-\mathbf{N}) .{ }^{*} P<0.05,{ }^{* *} P<0.01$ versus untreated control group $(0$ hours $)$. 
acting with other cellular receptors (eg, TLR2, TLR4, and RAGE). ${ }^{40}$ Similarly, soluble RAGE acts as a decoy by binding RAGE ligands (eg, HMGB1), and soluble RAGEHMGB1 complexes prevent HMGB1 from interacting with the cell surface RAGE. ${ }^{28}$ Thus, several molecules, including thrombomodulin and soluble RAGE, may suppress the increase in serum HMGB1 levels during development of indomethacin-induced small intestinal damage. A protective system to prevent excessive inflammation at injured areas and induction of remote tissue injury may thus exist in vivo.

There are two limitations to the present study. The first limitation is that we examined acute effects of NSAIDs, rather than the toxic effects of more chronic exposure. The second limitation is that we used much higher doses of both indomethacin and naproxen than are used clinically. However, we found that chronic administration of indomethacin was highly toxic, and mice that were daily administered $10 \mathrm{mg} / \mathrm{kg}$ indomethacin died within 4 days. It is therefore very difficult to evaluate chronic toxicity of NSAIDS to the small intestine. Furthermore, in a preliminary study, we investigated the ulcerogenic effect of a lower dose of indomethacin; neither a single dose nor a 1-week treatment of indomethacin at a dose of 1 $\mathrm{mg} / \mathrm{kg}$ induced macroscopic intestinal damage (data not shown). In animal studies, drugs are often used at higher doses in order to obtain sufficient effects of the drug, including adverse effects. In fact, most investigators have used higher doses of indomethacin (10 to $20 \mathrm{mg} / \mathrm{kg}$ ) in animal studies to induce macroscopic gastrointestinal damage, including gastric ulcers and small intestinal injury. ${ }^{4,24,41}$ We therefore think that the dose of indomethacin $(10 \mathrm{mg} / \mathrm{kg})$ used in the present study is appropriate.

In conclusion, these results suggest that HMGB1 may activate NF- $\kappa \mathrm{B}$ and MAPKs through TLR4, leading to the overexpression of inflammatory cytokines and the aggravation of damage in NSAID-induced enteropathy. Because LPS is a major exogenous ligand of TLR4, as well as a complicating factor for this damage, blocking TLR4 or inhibiting TLR4-dependent signal pathways may be a useful therapeutic option against NSAID-induced small intestinal injury.

\section{Acknowledgments}

We thank Emi Suzuki-Yoshioka and Emi Ohtsuki for their technical assistance.

\section{References}

1. Graham DY, Opekun AR, Willingham FF, Qureshi WA: Visible smallintestinal mucosal injury in chronic NSAID users. Clin Gastroenterol Hepatol 2005, 3:55-59

2. Sugimori S, Watanabe T, Tabuchi M, Kameda N, Machida H, Okazaki $H$, Tanigawa T, Yamagami H, Shiba M, Watanabe K, Tominaga K, Fujiwara Y, Oshitani N, Koike T, Higuchi K, Arakawa T: Evaluation of small bowel injury in patients with rheumatoid arthritis by capsule endoscopy: effects of anti-rheumatoid arthritis drugs. Digestion 2008 , 78:208-213

3. Watanabe T, Sugimori S, Kameda N, Machida H, Okazaki H, Tanigawa T, Watanabe K, Tominaga K, Fujiwara Y, Oshitani N, Higuchi K,
Arakawa T: Small bowel injury by low-dose enteric-coated aspirin and treatment with misoprostol: a pilot study. Clin Gastroenterol Hepatol 2008, 6:1279-1282

4. Watanabe T, Higuchi K, Kobata A, Nishio H, Tanigawa T, Shiba M, Tominaga K, Fujiwara Y, Oshitani N, Asahara T, Nomoto K, Takeuchi $\mathrm{K}$, Arakawa T: Non-steroidal anti-inflammatory drug-induced small intestinal damage is Toll-like receptor 4 dependent. Gut 2008, 57 : $181-187$

5. Hoshino K, Takeuchi O, Kawai T, Sanjo H, Ogawa T, Takeda Y, Takeda K, Akira S: Cutting edge: Toll-like receptor 4 (TLR4)-deficient mice are hyporesponsive to lipopolysaccharide: evidence for TLR4 as the Lps gene product. J Immunol 1999, 162:3749-3752

6. Dobrovolskaia MA, Medvedev AE, Thomas KE, Cuesta N, Toshchakov V, Ren T, Cody MJ, Michalek SM, Rice NR, Vogel SN: Induction of in vitro reprogramming by Toll-like receptor (TLR)2 and TLR4 agonists in murine macrophages: effects of TLR "homotolerance" versus "heterotolerance" on NF-kappa B signaling pathway components. J Immunol 2003, 170:508-519

7. Bustin M: Regulation of DNA-dependent activities by the functional motifs of the high-mobility-group chromosomal proteins. Mol Cell Biol 1999, 19:5237-5246

8. Park JS, Arcaroli J, Yum HK, Yang H, Wang H, Yang KY, Choe KH, Strassheim D, Pitts TM, Tracey KJ, Abraham E: Activation of gene expression in human neutrophils by high mobility group box 1 protein Am J Physiol Cell Physiol 2003, 284:C870-C879

9. Wang H, Bloom O, Zhang M, Vishnubhakat JM, Ombrellino M, Che J, Frazier A, Yang H, Ivanova S, Borovikova L, Manogue KR, Faist E, Abraham E, Andersson J, Andersson U, Molina PE, Abumrad NN, Sama A, Tracey KJ: HMG-1 as a late mediator of endotoxin lethality in mice. Science 1999, 285:248-251

10. Scaffidi P, Misteli T, Bianchi ME: Release of chromatin protein HMGB1 by necrotic cells triggers inflammation [Erratum appeared in Nature 2010, 467:622]. Nature 2002, 418:191-195

11. Andersson U, Wang H, Palmblad K, Aveberger AC, Bloom O, Erlandsson-Harris $\mathrm{H}$, Janson A, Kokkola R, Zhang M, Yang H, Tracey KJ: High mobility group 1 protein (HMG-1) stimulates proinflammatory cytokine synthesis in human monocytes. J Exp Med 2000, 192:565570

12. Yu M, Wang H, Ding A, Golenbock DT, Latz E, Czura CJ, Fenton MJ, Tracey KJ, Yang H: HMGB1 signals through Toll-like receptor (TLR) 4 and TLR2. Shock 2006, 26:174-179

13. Taguchi A, Blood DC, del Toro G, Canet A, Lee DC, Qu W, Tanji N, Lu Y, Lalla E, Fu C, Hofmann MA, Kislinger T, Ingram M, Lu A, Tanaka H, Hori O, Ogawa S, Stern DM, Schmidt AM: Blockade of RAGE-amphoterin signalling suppresses tumour growth and metastases. Nature 2000, 405:354-360

14. Maeda S, Hikiba Y, Shibata W, Onmae T, Yanai A, Ogura K, Yamada $\mathrm{S}$, Omata M: Essential roles of high-mobility group box 1 in the development of murine colitis and colitis-associated cancer. Biochem Biophys Res Commun 2007, 360:394-400

15. Davé SH, Tilstra JS, Matsuoka K, Li F, DeMarco RA, Beer-Stolz D, Sepulveda AR, Fink MP, Lotze MT, Plevy SE: Ethyl pyruvate decreases HMGB1 release and ameliorates murine colitis. J Leukoc Biol 2009, 86:633-643

16. Sawa H, Ueda T, Takeyama $Y$, Yasuda $T$, Shinzeki M, Nakajima $T$, Kuroda $Y$ : Blockade of high mobility group box-1 protein attenuates experimental severe acute pancreatitis. World J Gastroenterol 2006, 12:7666-7670

17. Tsung A, Sahai R, Tanaka H, Nakao A, Fink MP, Lotze MT, Yang H, Li J, Tracey KJ, Geller DA, Billiar TR: The nuclear factor HMGB1 mediates hepatic injury after murine liver ischemia-reperfusion. J Exp Med 2005, 201:1135-1143

18. Andrassy M, Volz HC, Igwe JC, Funke B, Eichberger SN, Kaya Z, Buss S, Autschbach F, Pleger ST, Lukic IK, Bea F, Hardt SE, Humpert PM, Bianchi ME, Mairbaurl H, Nawroth PP, Remppis A, Katus HA, Bierhaus A: High-mobility group box-1 in ischemia-reperfusion injury of the heart. Circulation 2008, 117:3216-3226

19. Wu H, Chen G, Wyburn KR, Yin J, Bertolino P, Eris JM, Alexander SI, Sharland AF, Chadban SJ: TLR4 activation mediates kidney ischemia/reperfusion injury. J Clin Invest 2007, 117:2847-2859

20. Myint KM, Yamamoto $Y$, Doi T, Kato I, Harashima A, Yonekura $H$, Watanabe T, Shinohara H, Takeuchi M, Tsuneyama K, Hashimoto N, Asano M, Takasawa S, Okamoto H, Yamamoto H: RAGE control of diabetic nephropathy in a mouse model: effects of RAGE gene dis- 
ruption and administration of low-molecular weight heparin. Diabetes 2006, 55:2510-2522

21. Ulloa L, Ochani M, Yang H, Tanovic M, Halperin D, Yang R, Czura CJ, Fink MP, Tracey KJ: Ethyl pyruvate prevents lethality in mice with established lethal sepsis and systemic inflammation. Proc Natl Acad Sci USA 2002, 99:12351-12356

22. Kaczmarek A, Brinkman BM, Heyndrickx L, Vandenabeele P, Krysko DV: Severity of doxorubicin-induced small intestinal mucositis is regulated by the TLR-2 and TLR-9 pathways. J Pathol 2012, 226:598-608

23. de Koning BA, van Dieren JM, Lindenbergh-Kortleve DJ, van der Sluis M, Matsumoto T, Yamaguchi K, Einerhand AW, Samsom JN, Pieters R, Nieuwenhuis EE: Contributions of mucosal immune cells to methotrexate-induced mucositis. Int Immunol 2006, 18:941-949

24. Watanabe T, Tanigawa T, Nadatani $Y$, Otani K, Machida H, Okazak $\mathrm{H}$, Yamagami H, Watanabe K, Tominaga K, Fujiwara Y, Arakawa T: Mitochondrial disorders in NSAIDs-induced small bowel injury. J Clin Biochem Nutr 2011, 48:117-121

25. Watanabe $T$, Nishio $H$, Tanigawa $T$, Yamagami $H$, Okazaki H, Watanabe K, Tominaga K, Fujiwara Y, Oshitani N, Asahara T, Nomoto K, Higuchi K, Takeuchi K, Arakawa T: Probiotic Lactobacillus casei strain Shirota prevents indomethacin-induced small intestinal injury: involvement of lactic acid. Am J Physiol Gastrointest Liver Physiol 2009, 297:G506-G513

26. Higuchi K, Umegaki E, Watanabe T, Yoda Y, Morita E, Murano M, Tokioka S, Arakawa T: Present status and strategy of NSAIDs-induced small bowel injury. J Gastroenterol 2009, 44:879-888

27. Park JS, Svetkauskaite D, He Q, Kim JY, Strassheim D, Ishizaka A, Abraham E: Involvement of Toll-like receptors 2 and 4 in cellular activation by high mobility group box 1 protein. $\mathrm{J}$ Biol Chem 2004 279:7370-7377

28. Liliensiek B, Weigand MA, Bierhaus A, Nicklas W, Kasper M, Hofer S, Plachky J, Gröne HJ, Kurschus FC, Schmidt AM, Yan SD, Martin E, Schleicher E, Stern DM, Hämmerling GG, Nawroth PP, Arnold B: Receptor for advanced glycation end products (RAGE) regulates sepsis but not the adaptive immune response. J Clin Invest 2004, 113:1641-1650

29. Barsness KA, Arcaroli J, Harken AH, Abraham E, Banerjee A, Reznikov L, Mclntyre RC: Hemorrhage-induced acute lung injury is TLR-4 dependent. Am J Physiol Regul Integr Comp Physiol 2004 287:R592-R599

30. Kim JY, Park JS, Strassheim D, Douglas I, Diaz del Valle F, Asehnoune K, Mitra S, Kwak SH, Yamada S, Maruyama I, Ishizaka A, Abraham E: HMGB1 contributes to the development of acute lung injury after hemorrhage. Am J Physiol Lung Cell Mol Physiol 2005, 288:L958-L965
31. Zeng S, Feirt N, Goldstein M, Guarrera J, Ippagunta N, Ekong U, Dun H, Lu Y, Qu W, Schmidt AM, Emond JC: Blockade of receptor for advanced glycation end product (RAGE) attenuates ischemia and reperfusion injury to the liver in mice. Hepatology 2004, 39:422-432

32. Fiuza C, Bustin M, Talwar S, Tropea M, Gerstenberger E, Shelhamer $\mathrm{JH}$, Suffredini AF: Inflammation-promoting activity of HMGB1 on human microvascular endothelial cells. Blood 2003, 101:2652-2660

33. Mitola S, Belleri M, Urbinati C, Coltrini D, Sparatore B, Pedrazzi M, Melloni E, Presta M: Cutting edge: extracellular high mobility group box-1 protein is a proangiogenic cytokine. J Immunol 2006, 176: $12-15$

34. Youn JH, Oh YJ, Kim ES, Choi JE, Shin JS: High mobility group box 1 protein binding to lipopolysaccharide facilitates transfer of lipopolysaccharide to CD14 and enhances lipopolysaccharide-mediated TNF-alpha production in human monocytes. J Immunol 2008, 180: 5067-5074

35. Dai S, Sodhi C, Cetin S, Richardson W, Branca M, Neal MD, Prindle T, Ma C, Shapiro RA, Li B, Wang JH, Hackam DJ: Extracellular high mobility group box-1 (HMGB1) inhibits enterocyte migration via activation of Toll-like receptor-4 and increased cell-matrix adhesiveness. J Biol Chem 2010, 285:4995-5002

36. Sappington PL, Yang R, Yang H, Tracey KJ, Delude RL, Fink MP: HMGB1 B box increases the permeability of Caco-2 enterocytic monolayers and impairs intestinal barrier function in mice. Gastroenterology 2002, 123:790-802

37. Yang R, Miki K, Oksala N, Nakao A, Lindgren L, Killeen ME, Mennander A, Fink MP, Tenhunen J: Bile high-mobility group box 1 contributes to gut barrier dysfunction in experimental endotoxemia. Am J Physiol Regul Integr Comp Physiol 2009, 297:R362-R369

38. Degryse B, Bonaldi T, Scaffidi P, Muller S, Resnati M, Sanvito F, Arrigoni G, Bianchi ME: The high mobility group (HMG) boxes of the nuclear protein HMG1 induce chemotaxis and cytoskeleton reorganization in rat smooth muscle cells. J Cell Biol 2001, 152:1197-1206

39. Esmon C: Do-all receptor takes on coagulation, inflammation. Nat Med 2005, 11:475-477

40. Abeyama K, Stern DM, Ito Y, Kawahara K, Yoshimoto Y, Tanaka M, Uchimura T, Ida N, Yamazaki Y, Yamada S, Yamamoto Y, Yamamoto $\mathrm{H}$, lino S, Taniguchi N, Maruyama I: The N-terminal domain of thrombomodulin sequesters high-mobility group-B1 protein, a novel antiinflammatory mechanism. J Clin Invest 2005, 115:1267-1274

41. Chiou SK, Tanigawa T, Akahoshi T, Abdelkarim B, Jones MK, Tarnawski AS: Survivin: a novel target for indomethacin-induced gastric injury. Gastroenterology 2005, 128:63-73 